\title{
Visitas domiciliárias a pessoas idosas - uma oportunidade de intervenção socioeducativa
}

\section{Home visits to older persons - an opportunity to socio-educational intervention}

\author{
Maria João Amante*, Susana Fonseca*, Lia Araújo** \\ * Instituto Politécnico de Viseu, ** Instituto Politécnico de Viseu e Universidade do Porto
}

\begin{abstract}
Resumo
O objetivo deste estudo consiste na avaliação da intervenção socioeducativa de Educadores Sociais, em contexto de visitas domiciliárias a pessoas idosas que vivem sozinhas. Trata-se dum estudo qualitativo de natureza exploratória, com recurso à análise documental de 28 relatórios. Da análise emergiram duas dimensões: Atividades, destacando-se a categoria Tipo de atividades, que revelou a diversidade da intervenção (estimulação motora, cognitiva, sensorial, de desenvolvimento pessoal e social, lúdicas); Avaliação, identifica-se a intervenção como muito positiva para os beneficiários, salientando-se a importância para redução da solidão. Concluiu-se que é de extrema importância, para além dos cuidados básicos, a intervenção socioeducativa em domicílio.

Palavras-chave: visitas domiciliárias, intervenção socioeducativa, solidão, pessoas idosas.
\end{abstract}

\begin{abstract}
The aim of this study is to evaluate the socio-educational intervention of Social Educators in the context of home visits to elderly people living alone. This is a qualitative study of exploratory nature, using the documentary analysis of 28 reports. From the analysis emerged two dimensions: Activities, highlighting the category Type of activities, which revealed the diversity of intervention (motor, cognitive, sensory stimulation, personal and social development, recreational); Evaluation, the intervention is identified as very positive for the beneficiaries, highlighting the importance for reducing loneliness. It was concluded that it is extremely important, in addition to basic care, socio-educational intervention at home.

Keywords: Home visits, Socio-educational intervention, loneliness, elderly.
\end{abstract}

Nos últimos anos tem-se constatado um número cada vez maior de pessoas idosas a viverem sozinhas e em quase completo isolamento, cujas causas, entre outras, se podem atribuir ao envelhecimento populacional e ao aumento da esperança média de vida, à desertificação dos centros urbanos por parte das famílias mais jovens, à constelação dos agregados familiares que não contemplam os mais idosos nos seus núcleos, e à rutura das relações de vizinhança, entre outros. A nível mundial a prevalência do isolamento social entre as pessoas com mais de 60 anos situa-se entre $7 \%$ e $14 \%$, dependendo da definição e das medidas utilizadas e o isolamento social percebido é mais severo nas pessoas entre 75-85 anos comparativamente com as de 57-65 anos (Cornwell \& Waite, 2009; Chen \& Schulz, 2016). Em Portugal, dados dos Census Séniores de 2017, indicam a existência de 28279 pessoas idosas a viverem sozinhas, 5124 a viverem isolados e 3521 a viverem isolados e sozinhos (GNR, 2017).

O isolamento social e a solidão poderão colocar as pessoas idosas numa situação de risco social, visto que estão mais vulneráveis a situações de deterioração física e cognitiva, ao aparecimento de depressões e até mesmo à morte (Hooyman \& Kiyak, 2009). O facto de estarem afastados da participação social contribui negativamente para um envelhecimento bem-sucedido.

Muitos programas e projetos têm surgido como resposta a esta problemática, nomeadamente através de respostas comunitárias de voluntariado e de respostas institucionais, como os serviços de apoio domiciliário. No entanto, as primeiras restringem-se, na sua maioria, a companhia e ajuda em pequenas atividades do quotidiano, e as segundas às necessidades básicas de higiene e alimentação. Partindo da premissa de que o isolamento potencia a deterioração física e cognitiva, bem como alterações do humor, tal como tem sido referido nos inúmeros estudos realizados acerca desta temática, respostas sociais que não contemplem a intervenção nestas áreas revelam-se manifestamente insuficientes. As Juntas de Freguesia, pela sua proximidade e conhecimento da população têm um lugar privilegiado para poderem serem motores de respostas comunitárias que vão para além das institucionalmente instaladas. Programas estruturados de estimulação e apoio socioeducativo em vistas domiciliárias a pessoas idosas que vivem sozinhas contribuiriam para que estes se mantivessem mais tempo nas suas habitações sem necessidade de institucionalização, mais tempo ativos e participativos e com menor perceção de isolamento e solidão.

O objetivo deste estudo consiste na avaliação da intervenção socioeducativa de Educadores Sociais, em contexto de visitas domiciliárias semanais a pessoas idosas que maioritariamente vivem sozinhos. 


\section{Método}

Trata-se de um estudo qualitativo de natureza exploratória, com recurso à análise documental de 28 relatórios finais de estágio do curso de licenciatura em educação social, de um Instituto Politécnico de Portugal. Os estágios foram realizados numa junta de freguesia urbana, de uma cidade com $19.7 \%$ de pessoas com 65 e mais anos e cujo índice de envelhecimento é de 137 (Pordata, 2015), no período compreendido entre 2012 e 2016.

De toda a informação constante nos relatórios, para este estudo, apenas foi considerada a referente às visitas domiciliárias planificadas e à avaliação das mesmas. Esta informação foi submetida a análise de conteúdo Assim, procedeu-se à codificação tendo sido escolhido como unidade de registo o tema e como regra de enumeração a frequência. $\mathrm{O}$ modo de categorização utilizado foi o temático (Mucchielli, 1972), tendo sido as categorias selecionadas à posteriori após leitura "flutuante" das respostas (Bardin, 1977). Os conteúdos presentes nos planos estruturados das visitas e na sua avaliação foram analisados com recurso ao software Nvivo, versão 11.

\section{Resultados}

Da análise de conteúdo emergiram duas dimensões, Atividades e Avaliação, as quais contribuem para uma análise da intervenção socioeducativa neste âmbito.

$\mathrm{Na}$ primeira dimensão - Atividades, foram definidas duas subcategorias: Objetivos e Tipo de Atividades. Relativamente aos Objetivos estes revelaram intenções de promoção do Envelhecimento ativo, Bem-estar (BES) físico, Bem-estar (BES) psíquico e Bem-estar (BES) social, sendo os dois últimos os mais referidos e estando presentes em 19 e 22 fontes respetivamente. O bem-estar físico foi o menos referido (11) em apenas 5 fontes (Tabela 1). Na categoria Tipo de atividades, a qual revelou a diversidade da intervenção, destacam-se 6 subcategorias: atividades de estimulação motora, cognitiva, sensorial, bem como, de desenvolvimento pessoal e social e ainda atividades lúdicas, de autonomia/AVD e de sensibilização e informação. Nesta destacam-se as atividades lúdicas com 60 referências, seguida das atividades de Estimulação cognitiva e sensorial com 55 referências e das de Desenvolvimento pessoal e social com 44.
Tabela 1.

Dimensão Atividades

\begin{tabular}{clcc}
\hline Categoria & \multicolumn{1}{c}{ Subcategoria } & Fontes & Ref. \\
\hline Objetivos & Envelhecimento ativo & 12 & 19 \\
& BES físico & 5 & 11 \\
& BES psíquico & 19 & 47 \\
& BES social & 22 & 41 \\
\hline Tipo & Autonomia /AVD & TOTAL & 118 \\
\hline & Desenvolvimento pessoal & 23 & 9 \\
& e social & & \\
& Estimulação cognitiva e & 16 & 55 \\
& sensorial & & \\
& Estimulação motora & 7 & 10 \\
& Lúdicas & 17 & 60 \\
& Sensibilização e & 10 & 19 \\
informação & & \\
\hline & & TOTAL & 197 \\
\hline
\end{tabular}

As atividades menos referidas foram as de Autonomia/AVD com apenas 9 referências.

O tipo de atividades dinamizadas pelos estagiários de educação social no que concerne à estimulação cognitiva e sensorial oscilaram entre a aplicação de programas estruturados (Ex: Making a Difference), a jogos de memória, jogos sensoriais, utilização de computador para pesquisa, adivinhas, provérbios, associações, etc. Relativamente às atividades de Desenvolvimento pessoal e social foram desenvolvidas conversas estruturadas com apelo às reminiscências e conversas não estruturadas sobre temáticas sugeridas e do agrado dos visitados. Nas lúdicas optou-se por jogos de tabuleiro (cartas e dominó) e manuais/artísticas, enquanto que as de sensibilização e informação abordaram temas como as burlas, a prevenção das quedas nos idosos, o reconhecimento do dinheiro e a utilização das novas tecnologias. As atividades de treino de Autonomia/AVD consistiram maioritariamente no acompanhamento em pequenas compras, ensino da utilização de números de emergência e em atividades de culinária. Por último, as de Estimulação Motora em caminhadas, passeios, pequenos exercícios de ginástica e jogos tradicionais.

$\mathrm{Na}$ segunda Dimensão - Avaliação, pretendia-se recolher e analisar informação que permitisse perceber a perceção do estagiário relativamente aos benefícios das visitas domiciliárias planificadas. A maioria dos relatórios analisados identifica este tipo de intervenção como muito positiva quer do ponto de vista do estagiário quer do beneficiário das visitas. Esta Perceção global positiva, foi definida como categoria de análise, sendo que na subcategoria, Estagiário, ela foi mencionada 34 vezes e na subcategoria, Participante se verificaram 55 referências (Tabela 2). Estes salientam a importância destas visitas para a redução da sua solidão e isolamento. Estas visitas são mesmo consideradas como um dos pontos fortes, pela maioria dos estagiários, comparativamente a outras atividades desenvolvidas no âmbito do estágio. 
Tabela 2.

Dimensão Avaliação

\begin{tabular}{clcc}
\hline Categoria & \multicolumn{1}{c}{ Subcategoria } & Fontes & Ref. \\
\hline Perceção & Do participante & 25 & 55 \\
Global & Do estagiário & 18 & 34 \\
Positiva & & & \\
\hline & & TOTAL & 89 \\
\hline Avaliação & Envelhecimento ativo & 9 & 17 \\
do & BES físico & 7 & 7 \\
estagiário & BES psíquico & 77 & 33 \\
& BES socio-relacional & 20 & 35 \\
\hline & & TOTAL & 92 \\
\hline Tipo de & Conversas & 2 & 3 \\
Avaliação & Observação & 9 & 9 \\
& Questionário & 18 & 25 \\
\hline & & TOTAL & 37 \\
\hline
\end{tabular}

A segunda categoria desta dimensão, Avaliação do Estagiário reúne informação da avaliação dos benefícios específicos, concordantes com os objetivos definidos da intervenção, mantendo-se assim, as 4 subcategorias: Envelhecimento ativo, Bem-estar (BES) físico, Bem-estar (BES) psíquico-cognitivo-emocional e Bem-estar (BES) socio-emocional. As que recolheram mais referências foram o Bem-estar (BES) socio-relacional (35) e o Bem-estar psíquico-cognitivo-emocional (33). A menos referenciada foi o Bem-estar físico (7). Relativamente ao Envelhecimento ativo foi referido que as pessoas retomaram atividades que já não executavam, tornando-se mais ativas e que aumentaram a participação em atividades da comunidade. Nos benefícios Físicos salientaram o aumento da atividade física em geral. Capacitação do domínio cognitivo, diminuição dos sentimentos de solidão, possibilidade de desabafar, sentimentos de alegria e de satisfação com a vida foram alguns dos aspetos categorizados em Bem-estar psíquico-cognitivo-emocional. $\mathrm{Na}$ subcategoria Bem-estar socio-relacional foram consideradas referências como troca de afeto, confiança, troca de ideias, sentimentos e conhecimentos, combate à exclusão social.

A última categoria desta Dimensão, Tipo de Avaliação inclui as diversas formas de avaliação utilizadas, sendo as subcategorias Conversas, Observação e Questionários. A mais referida (25) foi os Questionários, mais utilizados na avaliação final e preenchidos pelos participantes, seguidos da Observação (9) efetuada a partir de fichas de observação. As Conversas informais apenas são referidas 3 vezes e consistiam em conversas informais com os participantes acerca das atividades desenvolvidas nas visitas. Estes dois últimos tipos de avaliação eram efetuados de forma contínua geralmente no final de cada visita.

\section{Discussão dos Resultados}

A análise das dimensões consideradas permite-nos verificar que relativamente ao objetivo destas visitas são evidenciados o bem-estar psíquico e social, correspondendo a $74.6 \%$ das referências. As relações interpessoais que se estabelecem durante as visitas, bem como a interação durante o desenvolvimento das atividades planificadas, exigindo recurso a competências comunicacionais para o diálogo, recurso a memórias do passado, a crítica e discussão dos acontecimentos da atualidade, são aspetos que contribuem para o bem-estar psicológico e social. Frases como "Sendo que para as mesmas [participantes das visitas] estes momentos eram fulcrais para a sua vida" ilustram a perceção de bem estar das pessoas idosas que os estagiários tiveram das visitas. Por outro lado, os sentimentos de solidão e de isolamento são atenuados quando existe uma rotina de visitas que sabem serem apenas direcionadas para as suas necessidades de natureza afetiva e socioeducativa respeitando a sua individualidade. Tendo em conta que o processo de envelhecimento aumenta as diferenças inter-individuais (Paúl, Fonseca, Martín, \& Amado, 2005), esta metodologia permite considera-las de forma mais eficaz do que em situação de institucionalização. Por outro lado, vários estudos apontam para uma redução da mortalidade em indivíduos que têm relações sociais fortes, bem como efeitos positivos a nível da saúde física e mesmo no risco de demência (Dickens, Richards, Greaves, \& Campbell, 2011). A forma como estas visitas são percecionadas pelas pessoas idosas, no que concerne ao seu bem-estar pode ser ilustrada por afirmações (referidas pelas estagiárias) como "pediram que mesmo quando acabasse [o estágio], fossemos visitá-las, pois, tínhamos feito muita diferença nas suas vidas, nem que fosse só um dia por semana"

Relativamente ao tipo de atividades desenvolvidas foram mencionadas com maior frequência as lúdicas, de estimulação cognitiva e sensorial e de desenvolvimento pessoal e social. Vários estudos têm confirmado a importância da estimulação cognitiva das pessoas idosas (Hofland, Willis, \& Baltes, 1981; Falkenstein \& Sommer, 2006). e o seu papel para contrariar a ideia da irreversibilidade da deterioração das capacidades cognitivas associadas ao envelhecimento, demonstrando que as perdas se devem maioritariamente à ausência de treino dessas competências. Conjuntamente com estas atividades, as de lazer e de carácter social também revelam terem um efeito bastante positivo (Fernández-Ballesteros, 2011). A maioria das atividades de estimulação que são desenvolvidas são de carácter lúdico e cumprem o objetivo de trabalhar diversas áreas em simultâneo: física, cognitiva e social (Zimerman, 2000; Maroto, 2003).

A análise da avaliação feita pelos estagiários deste tipo de intervenção foi globalmente muito positiva. A avaliação feita pela maioria dos estagiários corrobora a importância atribuída a este tipo de intervenção afirmando mesmo que "das medidas implementadas em estágio o apoio individualizado foi sem dúvida a mais positiva". O bem-estar percebido quando estavam presentes e a preparação meticulosa à sua receção indiciava a importância da partilha desses momentos. Através das suas visitas, os estagiários de educação social contribuíram para que as pessoas idosas, mesmo sem saírem das suas, se sintam mais participativas, menos isoladas e com mais propósito de vida (Araújo, 2014).

$\mathrm{O}$ facto de terem sido referidos como maior benefício o bem-estar socio-relacional e o bem-estar 
psíquico-cognitivo-emocional é demonstrativo do efeito no bem-estar global das pessoas idosas. Como foi evidenciado pelas estagiárias, as queixas físicas diminuíram, voltaram a ser realizadas tarefas que já não eram executadas, foram aderindo a atividades cada vez mais complexas e alguns começaram a participar em atividades da comunidade. $E$, neste sentido, foi evidenciada a importância desta intervenção no isolamento e solidão.

Em síntese, pode-se concluir que, embora importantes as outras formas de intervenção, revela-se de extrema necessidade haverem respostas mais consistentes de intervenção socioeducativa, levada a cabo por técnicos, nomeadamente educadores sociais, para uma efetiva promoção de um envelhecimento bem-sucedido que vão para além dos cuidados de higiene e alimentação ou mesmo do suprimento do isolamento do ponto de vista relacional. Atividades de estimulação cognitiva, sensorial e motora, lúdicas, de informação/ sensibilização, de autonomia, desenvolvidas em domicílio, revelam-se muito importantes para o bem-estar das pessoas idosas que vivem na comunidade $\mathrm{e}$ contribuem para um envelhecimento bem-sucedido, o que reforça a urgência de este tipo de respostas ser considerado, nomeadamente pelas autarquias, que têm um melhor conhecimento das populações e das suas necessidades e condições de vida.

\section{Referências}

Araújo, L. (2014). A participação social das pessoas idosas. In S. Azevedo \& F. Correia (Coords), Educação e integração social - Livro de Actas do 3. ${ }^{\circ}$ Congresso Internacional de Educação Social (pp. 91-106). Porto: APTSES, Fronteira do Caos.

Bardin, L. (1977). Análise de Conteúdo. Lisboa: Edições 70.

Chen Y-RR, \& Schulz PJ. (2016). The Effect of Information Communication Technology Interventions on Reducing Social Isolation in the Elderly: A Systematic Review. Journal of Medicaç Internet Research, 18(1):e18.

Cornwell E.Y. \& Waite L. J. (2009). Social disconnectedness, perceived isolation, and health among older adults. Jounal of Health and Social Behaviour, 50(1), 31-48.

Dickens, A. P., Richards, S. H., Greaves, C. J., \& CampbelL, J. L. (2011). Interventions targeting social isolation in older people: a systematic review. Public Health, 11, 647. doi: 10.1186/1471-2458-11-647.

Falkenstein, M. \& Sommer, S. (2006). Os benefícios do tempo. In: Ferrari, A.C. (Ed.). Viver mente \& cérebro (pp. 26-31). São Paulo: Duetto.

Fernández-Ballesteros, R. (2011). Positive aging: objective, subjective and combined outcomes. E-Journal of Applied Psychology, 7, 22-30.

GNR, Guarda Nacional Republicana (2017). Operação Censos Sénior 2017 - Resultados. Disponível em: http://www.gnr.pt/comunicado.aspx?linha=4206

Hofland, F., Wills, L., \& Baltes, B. (1981). Fluid intelligence performance in the elderly: Intraindividual variability and cognitions of assessment. Journal of educational Psychology; 73, 573-586.

Hooyman, N. R. \& Kiyak. H. A. (2009) Social Gerontology A Multidisciplinary Perspective (8th ed.), Boston: Pearson.

Maroto, M. (2003). Programa de Estimulação de Memória - Estimulação e manutenção de funções cognitivas em idosos. Lisboa: Cegoc-Tea.

Mucchielli, R. (1972). Opinions et changement d'opinion: connaissance du probléme, application et pratiques. Paris : Editions ESF.

Paúl, C., Fonseca, A., Martín, I, \& Amado, J. (2005). Satisfação e qualidade de vida em idosos portugueses. In C. Paúl \& A. Fonseca (Coords.). Envelhecer em Portugal: Psicologia, saúde e prestação de cuidados (pp. 77-96). Lisboa: Climepsi Editores.

Pordata (2015). Números dos municípios e regiões de Portugal. Disponível em: http://www.pordata.pt/Municipios/Quadro+Resumo/V iseu+(Munic\%C3\%ADpio)-8520

Zimerman, G. I. (2000). Velhice: aspectos biopsicossociais. Porto Alegre: Artes Médicas.

\section{Agradecimentos}

Ao Centro de Estudos em Educação, Tecnologias e Saúde (CI\&DETS) do Instituto Politécnico de Viseu e aos estagiários de Educação Social, autores dos relatórios analisados. 